\title{
Influence of Different Application of Lubricants on Wear and Pre-existing Rolling Contact Fatigue Cracks of Rail Materials
}

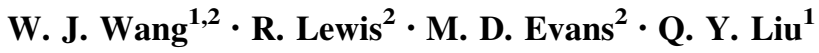

Received: 9 November 2016/Accepted: 20 March 2017/Published online: 31 March 2017

(c) The Author(s) 2017. This article is an open access publication

\begin{abstract}
Rolling contact fatigue (RCF) of rail can be a significant problem affecting safety and maintenance. Rail materials have been optimized to reduce it, but not enough is known about how friction management products applied to the rail affect crack growth. This study presents experimental results carried out to explore the influence of different lubricants and application orders on wear and preexisting RCF cracks in rail materials. The results indicate that the types or properties of lubricants have a vital role in the wear rate and fatigue crack growth characteristics of rail materials after conditioning with 5000 dry cycles to initiate cracks. Using a different application order of two lubricants has a significant influence on the crack growth angles in the rail rollers.
\end{abstract}

Keywords Rail - Lubricant - Water · RCF crack · Application order

\section{Introduction}

Rolling contact fatigue has an important role in determining the operational reliability of the wheel/rail system. Therefore, the control of RCF-related defects is an ongoing concern for both safety and the cost of railway transportation [1]. For example, there are many oblique cracks on the railway wheel and rail surfaces, which may cause

R. Lewis

Roger.Lewis@sheffield.ac.uk

1 Tribology Research Institute, Southwest Jiaotong University, Chengdu 610031, China

2 Department of Mechanical Engineering, University of Sheffield, Mappin Street, Sheffield S1 3JD, UK complete failure of rail and potential derailment. As reviewed in previous literature, many researchers have worked to clarify RCF mechanisms of wheels and rails and explored preventive measures using experimental studies and numerical models [2-6].

RCF defects of wheel and rail materials are mainly caused by cyclic loading of the wheel/rail interface. In fact, there is a competitive relationship between wear and RCF damage and the wear has an important role in enhancing rail fatigue life [7]. Reducing wear problems may lead to more RCF or other competitive types of wheel/rail damage. Therefore, the wear rate is significant for controlling the initiation and propagation of wheel/rail RCF cracks [8]. Donzella established a simulation model for assessing the wear and RCF in rails with particular emphasis on their competitive role, and the results indicated that the wear can remove the surface cracks due to RCF [9]. It is noted that the initiation and propagation of cracks are affected by lots of factors, such as the microstructure of materials, contact pressure, shear stress, lubricant and operational environment.

Under the cyclic contact loading condition, RCF cracks initiate and grow when the stress in the contact zone exceeds the elastic shakedown limit of wheel and rail materials. Meanwhile, the crack propagation is associated with the microstructure of materials and the development of strain hardening [10]. Carroll discussed the relationship between the rail decarburization and RCF, and the effect of decarburization was to increase the rail crack growth rate with increasing depth [11]. A sensitivity analysis revealed a strong influence of fatigue strength and material defect distribution on the probability of fatigue failure [12]. The crack initiation occurs on the material surface or sub-surface, and the sub-surface crack initiation requires a stress concentration caused by a large material defect, such as a void or inclusion [13]. 
Evidence has been provided to show that as the plastic deformation exceeds the fracture strain of the material, a surface crack is formed. Increasing slip ratio causes an increase in the traction coefficient, and the fatigue strength decreased simultaneously, which would easily accelerate the crack initiation [14]. Furthermore, the cracks propagate not only due to the rolling contact loading, but also owing to the influence of low viscosity fluid [15]. Fluids (e.g. rain water) are commonly present in the wheel/rail interface, and lubricants including oil and grease are frequently used to reduce the wear of wheel and rail. Water greatly reduces the wear rate of wheel/rail and transforms the damage mechanism of wheel and rail materials. Meanwhile, water in the wheel/rail interface may lead to localized corrosion and hydrogen uptake in the rail, further increasing the likelihood of cracking [16]. The performance of different grease types as curve lubricants has been assessed, and there is an inverse relationship between the retentivity and wear rates [17]. Grease significantly changes the contact conditions for wear transitions of wheel/rail materials [18]. Descartes performed wheel flange/rail contact lubrication tests in the laboratory for understanding wheel/rail lubricating mechanisms [19]. However, the effects of different lubricants on RCF characteristics were not investigated.

The water and oil often bring about low adhesion phenomena in the wheel/rail interface. Furthermore, the leaf slurry due to the leaf residue film formation would cause low adhesion [20]. If oil and water are present together (regardless of amount), oil has the dominating effect and adhesion coefficient remains at low levels similar to having oil alone [21]. At present, many friction modifiers (FM) have been used to improve the friction level of the wheel/ rail interface [22, 23]. The wheel/rail interfacial friction coefficient is strongly dependent on the rheological properties of third-body layer from different FMs. An engineered friction modifier has been used to significantly reduce the rail wear and eliminate the development of head check and surface cracks [24]. Hardwick et al. [25] produced a new $T \gamma / A$ wear curves under the dry, water and grease lubricated conditions and proved that less wear and deformation is found under the water condition. At the same time, the application of water accelerates the propagation of pre-existing cracks and the increase in RCF damage is inversely proportional to the viscosity of the fluids [1]. Furthermore, the friction level of the wheel/rail interface influences the shakedown state of wheel and rail materials. The use of water or lubricants would place the materials within the elastic shakedown limit regime and far away ratcheting regime, which benefits to reducing the plastic deformation accumulation and fatigue damage.

It is worth noting that water and other lubricants may be present together in the wheel/rail contact, which could bring a significant influence on RCF of wheel/rail materials. In view of this, the influence of different application of lubricants on the wear and RCF of rail materials was investigated using a twin-disc machine. Particularly, the formation and propagation characteristics of cracks were explored using various types of post-test analysis.

\section{Experimental Procedure}

\subsection{Twin-disc Machine}

The Sheffield University Rolling Sliding (SUROS) tester was used to perform the RCF experiments. Details of the tester usage and capabilities have been described previously [26]. A torque sensor (measurement error $\pm 2 \%$ ) mounted on the shaft of upper specimen continually monitors the torque (it can be used to calculate traction or braking force). The specimen discs are hydraulically loaded together and driven at controlled speeds by independent motors. A load cell (measurement error: $\pm 2 \%$ ) mounted under the hydraulic jack ensures that the required load (normal force) is continually applied. Slip levels are achieved by alteration of the rotational speed of an AC motor. A wheel specimen (lower disc) acts as the driving disc, and a rail specimen (upper disc) acts as the brake for simulating an accelerating wheelset.

\subsection{Experimental Materials and Parameters}

The wheel and rail cylindrical discs were cut along R8T wheel rim and 260 grade rail head parallel, and as close as possible to the outer surface. All discs were machined to a diameter of $47 \mathrm{~mm}$ with a contact track width of $10 \mathrm{~mm}$. The contact surfaces were ground to reach a roughness $\left(R_{\mathrm{a}}\right)$ of about $1 \mu \mathrm{m}$.

A rotational speed of $400 \mathrm{r} / \mathrm{min}$ (about $1 \mathrm{~m} / \mathrm{s}$ surface speed) of rail disc, a maximum contact pressure of $1500 \mathrm{MPa}$ and $1 \%$ slip ratio were used for all experiments. These test parameters are typical of previous twin-disc studies on RCF $[1,26,27]$. The previous work proved that the rail roller experiencing 5000 dry cycles reaches a transition stage and initiates visible cracks [1]. It this study, the tests were run under dry condition firstly for 5000 cycles in order to preexisting RCF cracks in the rail discs and then for a further 25,000 cycles with a different application of lubricants. So the total number of cycles of a rail disc is 30,000. For comparing the effect of lubricants on RCF cracks, two dry tests, with 5000 and 30,000 cycles, respectively, were carried out. All experimental conditions are given in Table 1.

In the testing process, the lubricants including water, oil and grease were applied in different orders. The synthetic oil used is a typical TOR (top of rail) product used in North America (described as a "synthetic-organic" fluid, non- 
Table 1 Experimental conditions

\begin{tabular}{llrl}
\hline Test & Lubricant & Dry cycles & Lubricant cycles \\
\hline D1 & No & 5000 & 0 \\
D2 & No & 30,000 & 0 \\
W1 & Water & 0 & 30,000 \\
W2 & Water & 5000 & 25,000 \\
O1 & Oil & 0 & 30,000 \\
O2 & Oil & 5000 & 25,000 \\
G1 & Grease & 0 & 30,000 \\
G2 & Grease & 5000 & 25,000 \\
WO & Water, oil & 5000 & First water $(12,500)$ and then oil $(12,500)$ \\
OW & Water, oil & 5000 & First oil $(12,500)$ and then water $(12,500)$ \\
MWO & Water, oil & 5000 & Mixture of water and oil $(25,000)$ \\
WG & Water, grease & 5000 & First water $(12,500)$ and then grease $(12,500)$ \\
GW & Water, grease & 5000 & First grease $(12,500)$ and then water $(12,500)$ \\
MWG & Water, grease & 5000 & Mixture of water and grease $(25,000)$ \\
\hline
\end{tabular}

water soluble, with a pour point of $-40{ }^{\circ} \mathrm{C}$ and ideal gravity of $0.85-0.89$ ), and the gauge face lubricant grease is one approved for use in the UK for rail gauge corner lubrication (described as a biodegradable ester-based grease with a pour point of $<-30{ }^{\circ} \mathrm{C}$ and a viscosity at $40{ }^{\circ} \mathrm{C}$ of $45 \mathrm{cSt}$ ). Running water was added to the surface of rail disc using a channel at a rate of about 2 drops per second. Oil and grease were applied manually, to the disc surfaces through a syringe.

All experiments were performed under the ambient temperature of $22-26{ }^{\circ} \mathrm{C}$ and humidity of $30-50 \%$ conditions. The wheel and rail discs were cleaned in ethanol, dried and weighed using an electronic balance (accuracy $0.0001 \mathrm{~g}, \mathrm{BS} 224 \mathrm{~S}$ ) before and after testing. The wear rates of rail rollers were measured by mass loss $(\mu \mathrm{g})$ per rolling cycle. The hardness of rail discs was measured using a Vickers hardness instrument (MVK-H21). The surface roughness was recorded using a stylus profilometer (SJ500). The wear surface damage and wear debris were examined using a scanning electronic microscopy (SEM) (JSM-7001F). The longitudinal sections cut along the rolling direction were prepared by mounting in resin, grinding to 2000 grit silicon carbide paper, polishing to $0.5 \mu \mathrm{m}$ with diamond paste and etching with natal (4\% $\mathrm{HNO}_{3}$ in ethanol) for observing cracks in the rail discs by means of optical microscopy (OM) (OLYMPUS BX60M) and SEM (JSM-7001F).

\section{Results}

\subsection{Traction Coefficient and Wear Rate}

It is found from Fig. 1a that the traction coefficient (the ratio of traction force to normal force in the wheel/rail interface) of an unlubricated wheel/rail contact increases rapidly at first with an increase in the number of cycles and then decreases and maintains a value from about 4000 cycles. When the water, oil or grease is added to the contact interface after 5000 dry cycles, the traction coefficient reduces significantly. The average value under the grease condition is the smallest (Fig. 2). When the lubricants are used at the beginning of testing, the traction coefficient keeps a low level compared with the dry condition. Furthermore, the traction coefficient is smaller when the lubricant is applied from the beginning under the same lubricant conditions (Fig. 2). The reason for this is that the surface damage is serious under the use of lubricant with 5000 dry cycles, which causes large surface roughness of rail rollers. Particularly, the fluctuating behaviour of traction coefficient is obvious due to the reapplication of oil and grease.

Under the water and oil conditions (Fig. 1b), the traction coefficient further reduces markedly when the oil is applied after 17,500 water cycles (WO test). For the OW test, the traction coefficient rises gradually with the use of water after 17,500 cycles due to remaining oil. When the mixture of water and oil is added, the traction coefficient fluctuates due to the fact the oil and water do not mix well so sometimes oil is in the contact and sometimes not. For the water and grease conditions (Fig. 1c), the traction coefficient has similar changes compared to the water and oil conditions. Average traction coefficient (the arithmetic mean value of dynamic traction coefficient from the beginning of tests or after 5000 dry cycles) of the lubricated wheel/rail contact in Fig. 2 shows that there is almost same value when the water and oil or water and grease (WO and OW tests, WG and GW tests) are used, respectively, for 12,500 cycles. The application order of lubricants has no influence on average traction coefficient of the 

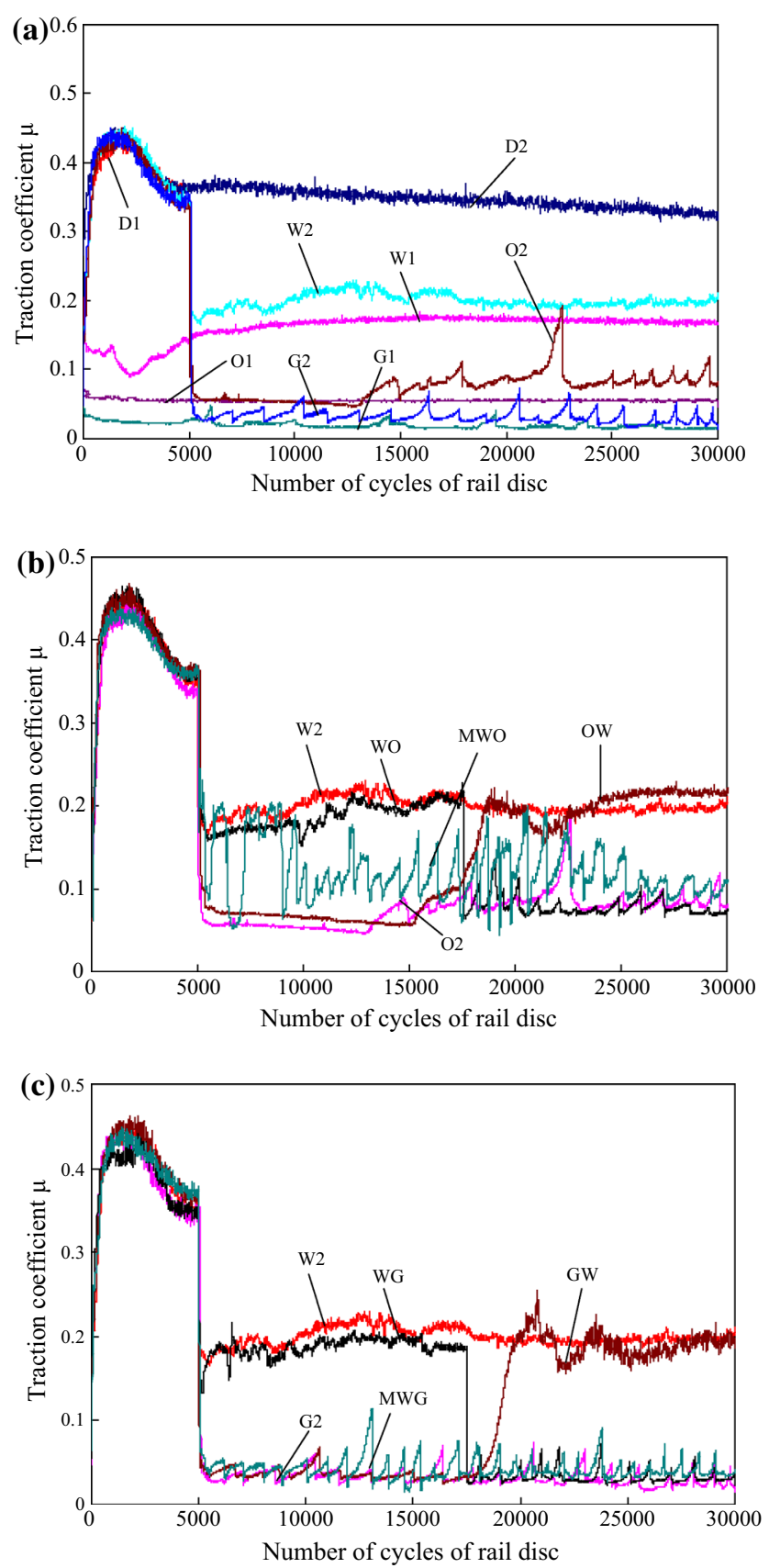

Fig. 1 Traction coefficient of wheel/rail under, a the dry, water, oil and grease conditions; $\mathbf{b}$ the water and oil conditions; $\mathbf{c}$ the water and grease conditions

wheel/rail interface. However, average traction coefficient under the mixture of water and oil or water and grease conditions (MWO and MWG tests) is lower compared with respective application of lubricants. This result indicates that different application of lubricants would influence the traction coefficient of the wheel/rail interface.

It is visible from Fig. 3 that the wear rates (mass loss per rolling cycle of the rail disc) of rail discs are very small when the wheel/rail interface was lubricated for the whole test and that oil and grease lubricants present excellent wear-reducing performance. After dry pre-testing was carried out for 5000 cycles, the application of lubricants causes a significant increase in wear rates of rail materials compared with the dry condition. Catastrophic wear of rail discs may result from the growth of large thin tongues of material that then break away from the surface. Furthermore, water causes the maximal wear rate of the rail disc (W2 test) and the wear rate is minimal under the grease lubrication conditions after 5000 dry cycles (G2 test). It should be noted that different application order of lubricants (water, oil and grease) can bring about different wear rates of rail discs. The wear rates under the water and oil conditions are lower than that of the water and grease conditions when the application order is the same. The mixture of two lubricants leads to more serious wear of rail materials compared with their respective application.

\subsection{Damage Behaviour}

SEM micrographs of worn surfaces of rail discs under different conditions are shown in Figs. 4 and 5. It is found from Fig. 4a that the damage is slight after 5000 dry cycles and there is visible fatigue crack growth in the rolling direction, as shown in Fig. 6a. Furthermore, the surface roughness is very small (Fig. 7). With an increase in number of cycles, the damage and surface roughness aggravates (Fig. 7) and mild surface fatigue appears on the worn surface (Fig. 4b) and the cracks propagate at a shallow angle under the dry condition (Fig. 6b).

When the wheel/rail interface is lubricated from the beginning of testing, the surface damage is very slight (Fig. 4c) and there is mild ploughing under the oil and grease conditions (Fig. 4e, g). Furthermore, the use of lubricants results in serious surface delamination and fatigue damage when the dry 5000 cycles pre-testing is carried out. Some thin metal tongues can be found on the surface of rail discs (Fig. 4d, f, h). Compared with the water and oil conditions, the delamination lightens and there is obvious shelling damage under the grease condition (Fig. 4h). Therefore, different surface damage brings the variety of surface roughness of rail discs under various lubrication conditions (Fig. 7).

When two lubricants (water and oil or water and grease) are applied in turn, the surface presents obvious delamination and fatigue damage. However, it is observed from Fig. 5 that the degree of surface damage exhibits some differences due to the different application order of two lubricants. For the WG and MWG tests, obvious shelling appears on the rail discs surface owing to grease characteristic (Fig. 5d, f). With an increase in number of cycles, the size of thin metal tongue increases. Once the size reaches a critical value, the metal tongue would fracture 
Fig. 2 Average traction coefficient of simulated wheel/ rail interface

Fig. 3 Wear rates of rail discs
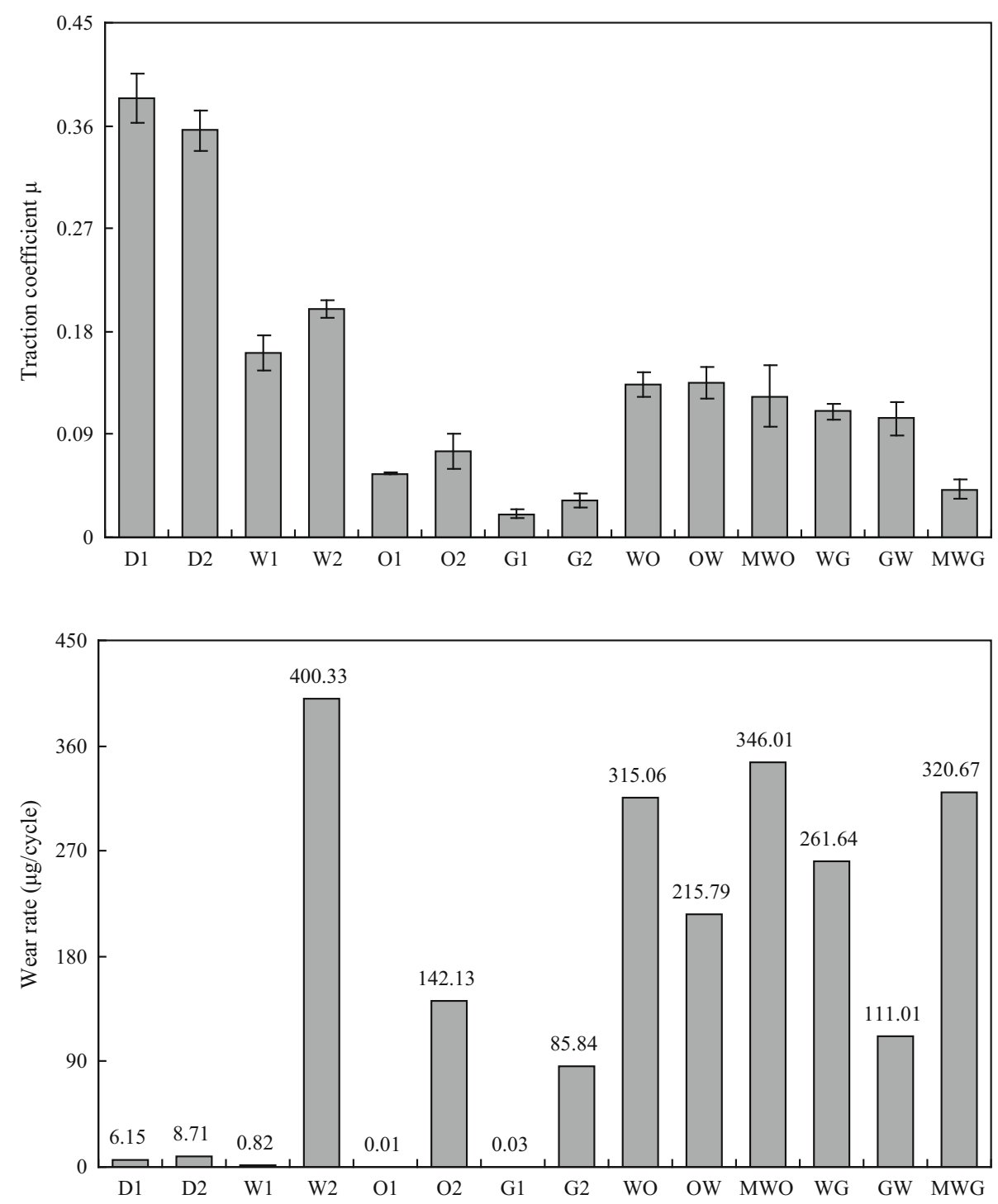

due to the cyclic contact loading, which causes the formation of wear debris and removal of rail material (Fig. 8). It is visible that the wear debris presents a laminar structure with various sizes and there is no obvious difference for water, oil and grease lubricants.

The hardness variation of the rail disc sections represents the pattern of sub-surface shear deformation of the materials. The results in Fig. 9 indicate that the hardness decreases gradually and near the bulk value of the rail material with increasing depth below the surface of except for the $\mathrm{W} 1, \mathrm{O} 1$ and G1 tests. The dry pre-testing with 5000 cycles has brought obvious plastic deformation (Fig. 10a). So, the use of different lubricants after 5000 dry cycles would not change the hardening location. However, when the lubrication lasts for the whole test, low traction coefficient causes the maximum hardening and shear stress to be located the sub-surface of the rail disc (W1, O1 and G1 tests), and then, there is an obvious deformation layer on the sub-surface (Fig. 10b), which results in no visible surface fatigue damage. Furthermore, different type and application order of lubricants has an important influence on the hardening behaviour of rail discs (Fig. 9).

\subsection{Crack Growth Behaviour}

The rail disc experiencing 5000 dry cycles has visible fatigue cracks in the rolling direction (Fig. 6a). The use of lubricants after 5000 dry cycles causes a rapid growth of RCF cracks, as shown in Figs. 11, 12 and 13. The crack length increases with an increase in the cycles, which results in the appearance of wear debris with a laminar structure and mass loss of materials. The material removal due to wear and the crack growth are mutually competitive 
Fig. 4 SEM micrographs of worn surface of rail discs, a D1; b D2; c W1; d W2; e O1; f O2; g G1; h G2

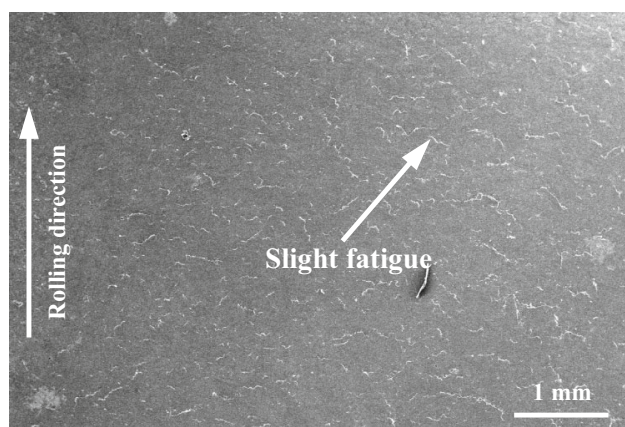

(a)

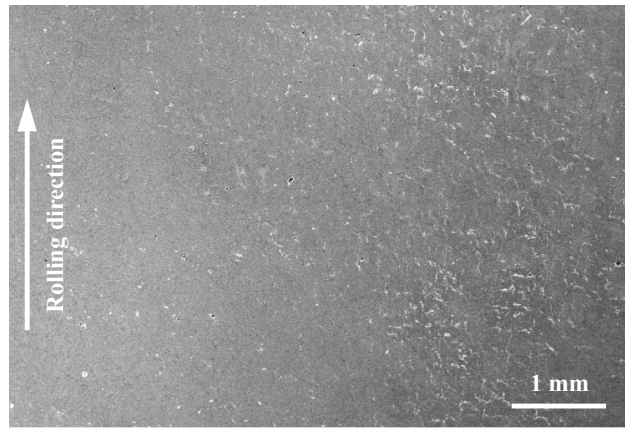

(c)

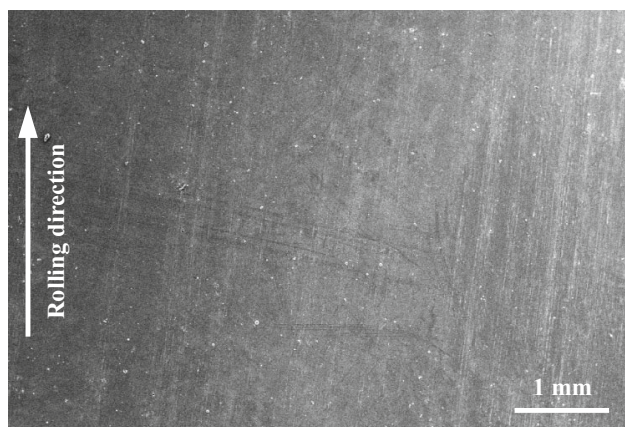

(e)

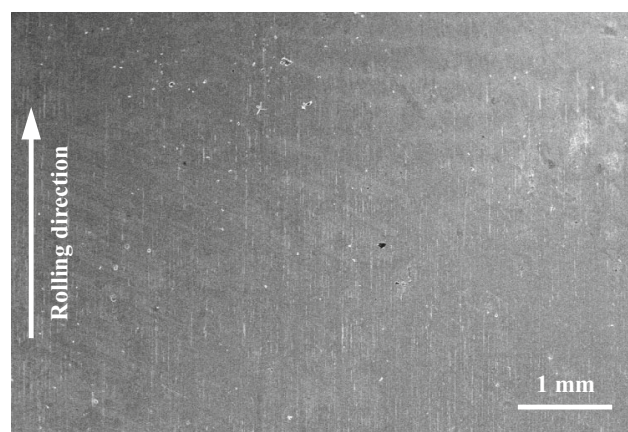

(g)

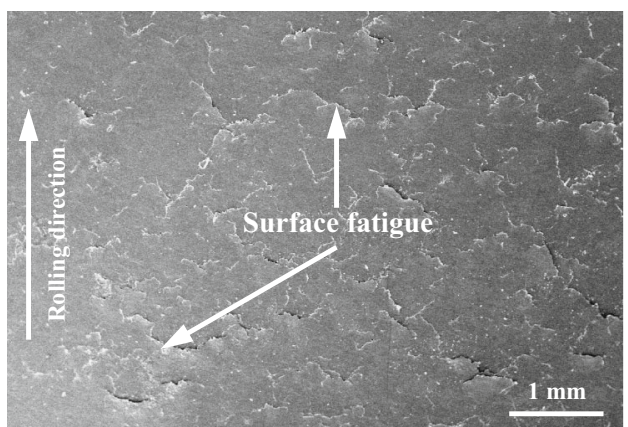

(b)

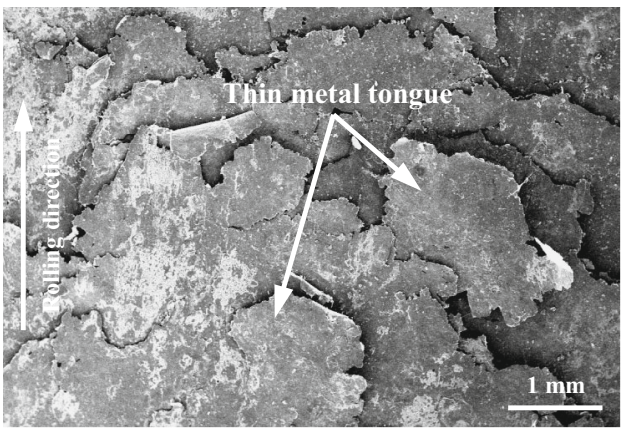

(d)

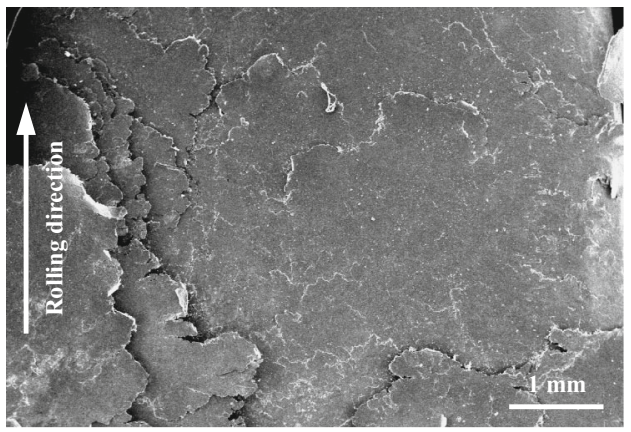

(f)

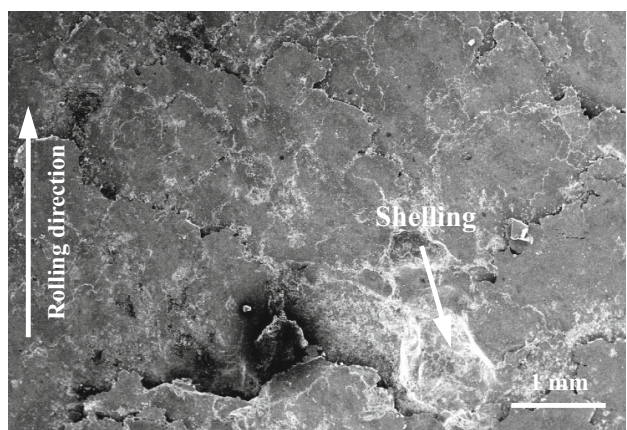

(h)
$[7,8]$. In view of this study, real crack growth rates (crack growth per cycle) are determined by means of the sum of measured crack length $\left(L_{\mathrm{m}}\right)$ and the crack wear length due to surface wear $\left(L_{\mathrm{w}}\right)$, shown in Fig. 14a. The crack wear length is calculated by means of the difference between original radius $(23.5 \mathrm{~mm})$ and real radius after wear and the crack angle $(\theta)$. The growth rate of cracks and crack angle of rail discs are shown in Fig. 14b, c. 
Fig. 5 SEM micrographs of worn surface of rail discs, a WO; b OW; c MWO; d WG; e GW; f MWG

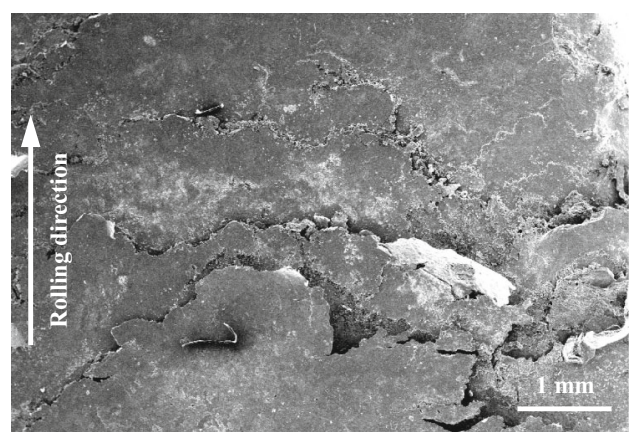

(a)

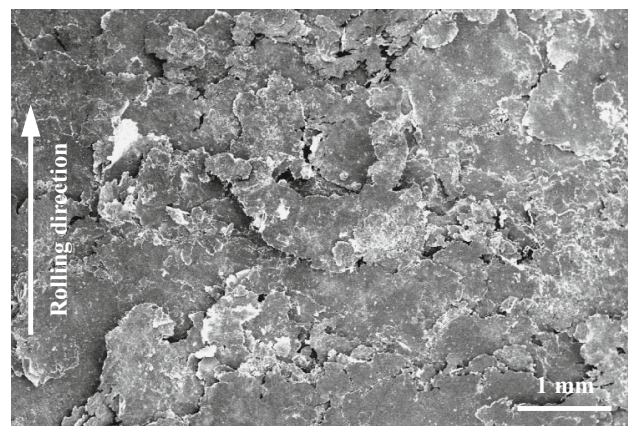

(c)

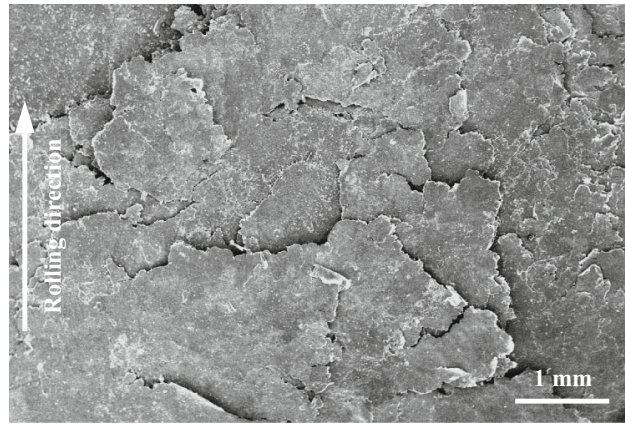

(e)

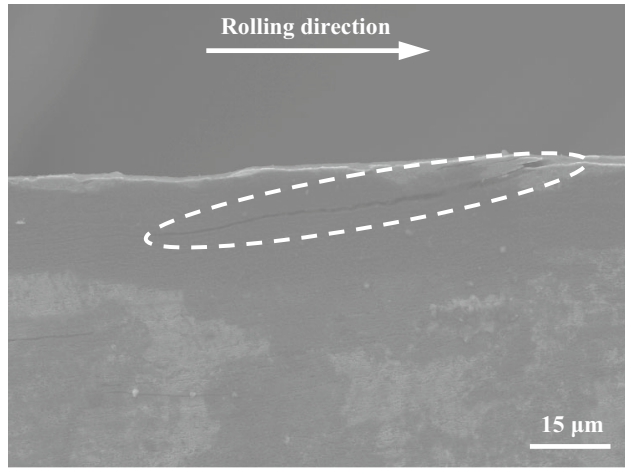

(a)

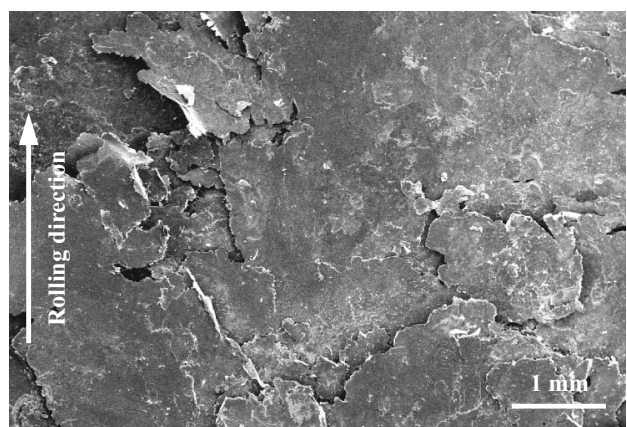

(b)

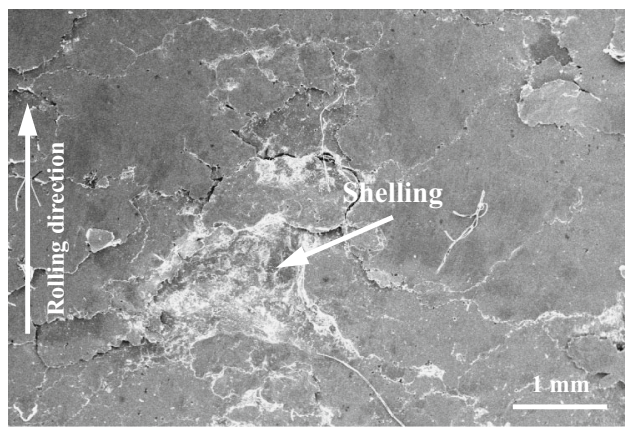

(d)

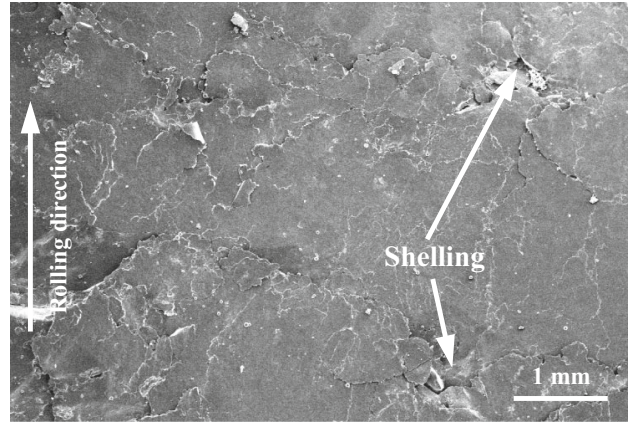

(f)

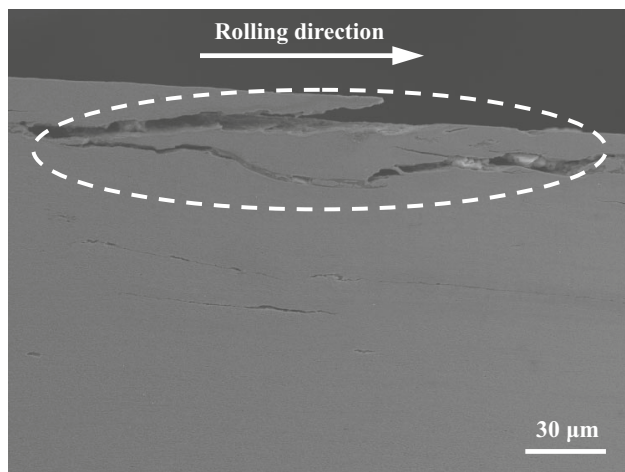

(b)
It is found that many cracks are distributed along the rolling direction of the rail discs and propagate at different angles. Under the dry pre-testing and water conditions, the crack reaches a maximum measured length of $2389 \mu \mathrm{m}$ and the growth angle of cracks ranges from $6^{\circ}$ to $14^{\circ}$. Average and maximum crack growth rates (statistical 
Fig. 7 Surface roughness of rail discs

Fig. 8 SEM micrographs of wear debris, a W2; b O2; c G2

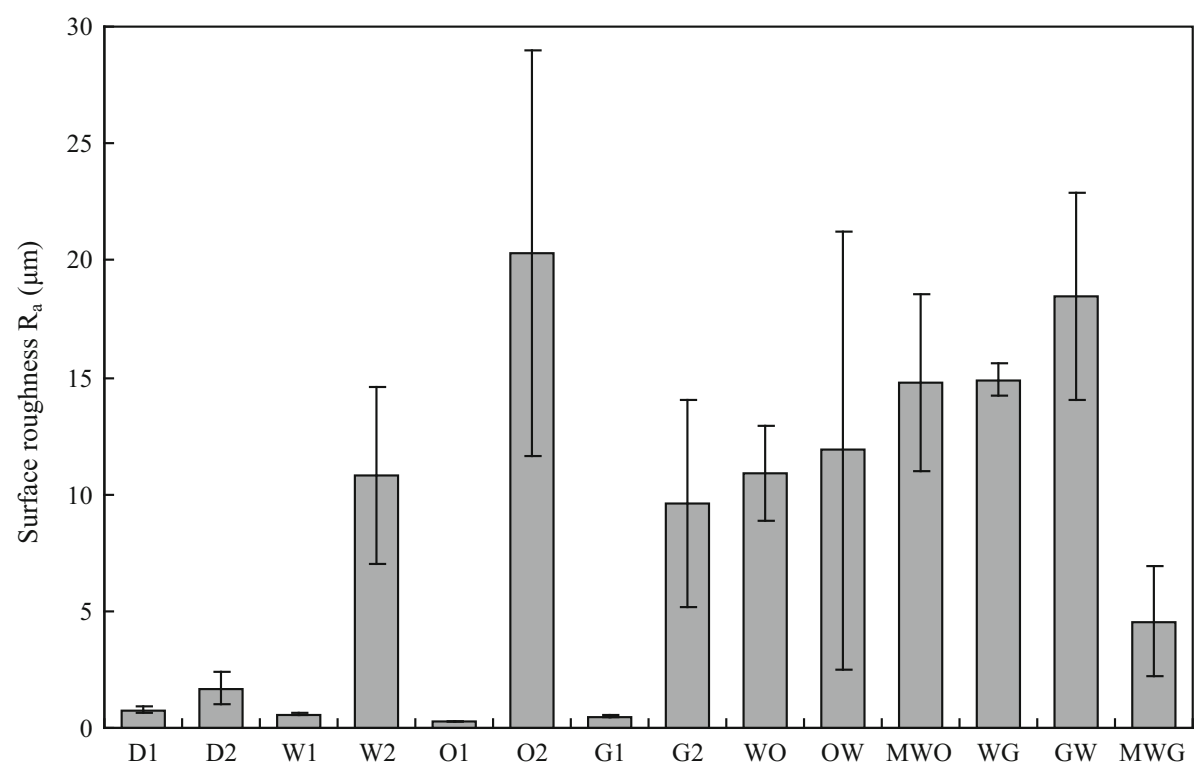

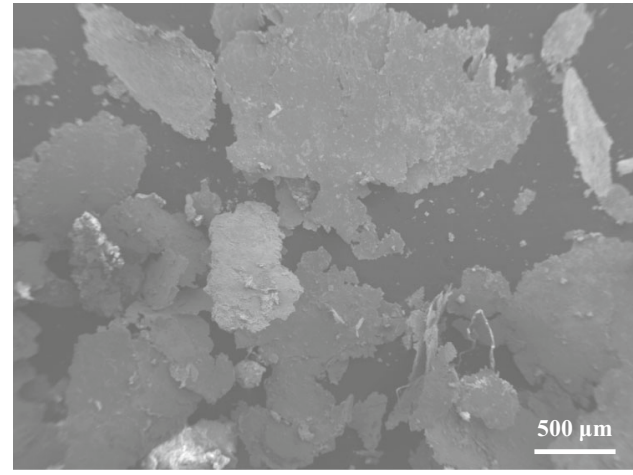

(a)

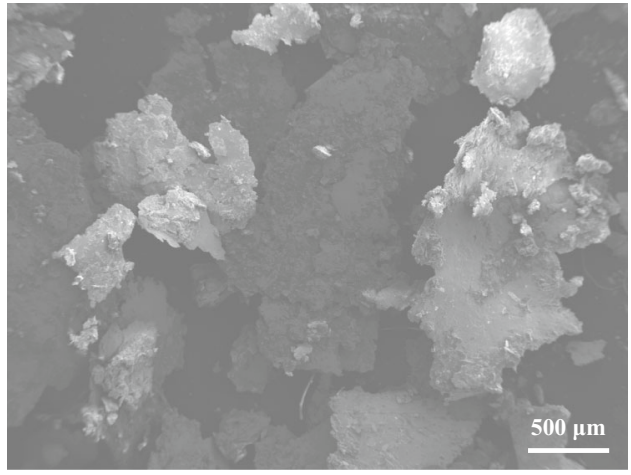

(b)

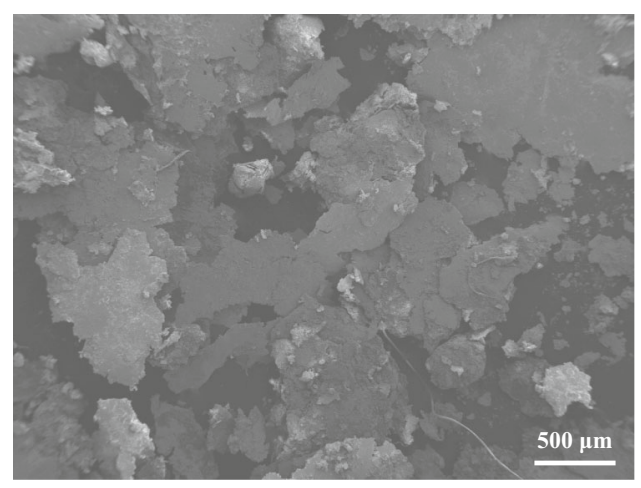

(c)

results of many cracks from one rail disc) reach a maximum for the water condition. When oil or grease is used (Fig. 11b, c), the growth angle of cracks increases (Fig. 14c) and marked branch cracks appear. The average crack angle of the oil and grease condition is $14.0^{\circ}$ and $24.1^{\circ}$, respectively, owing to different crack growth mechanism. Particularly, it is found in Figs. $4 \mathrm{~h}$ and $11 \mathrm{c}$ that obvious shelling appears due to the formation and connection of branch cracks under the oil condition. Compared to the water condition, the crack growth rate reduces significantly under the oil and grease conditions (Fig. 14b).

When water and oil are used, the application order influences the crack growth rates and crack angle of rail 

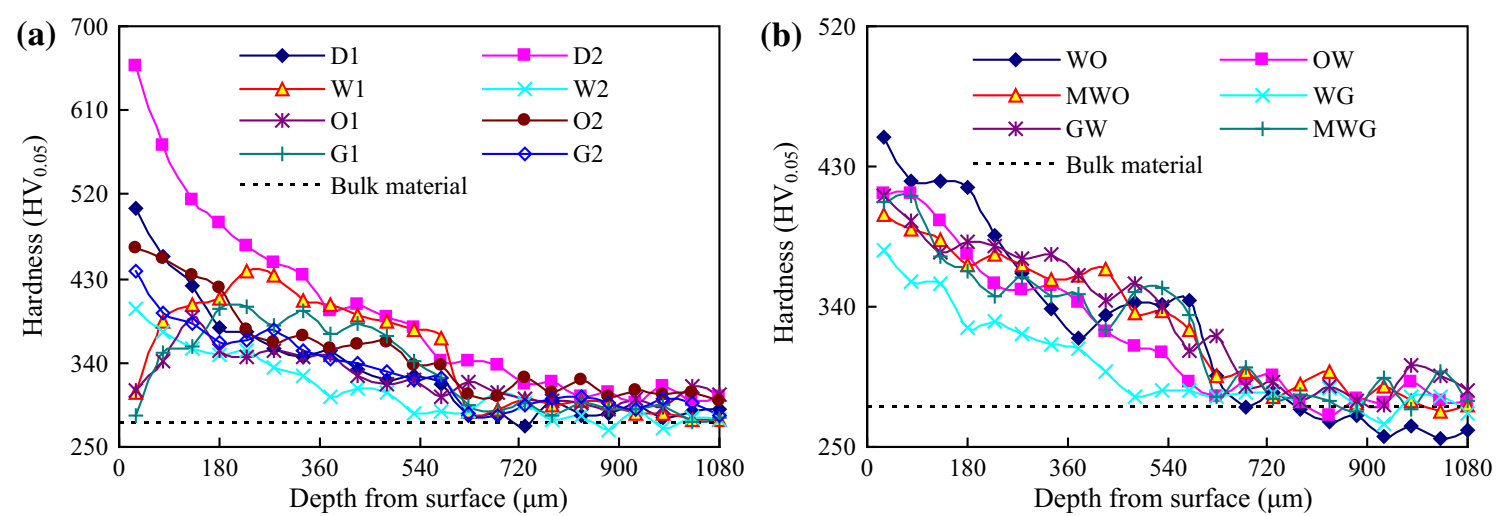

Fig. 9 Hardness variation with depth below surface of rail discs, a different lubricant conditions; $\mathbf{b}$ different application order of lubricants

Fig. 10 OM micrographs of plastic deformation of rail discs, a D1; b W1

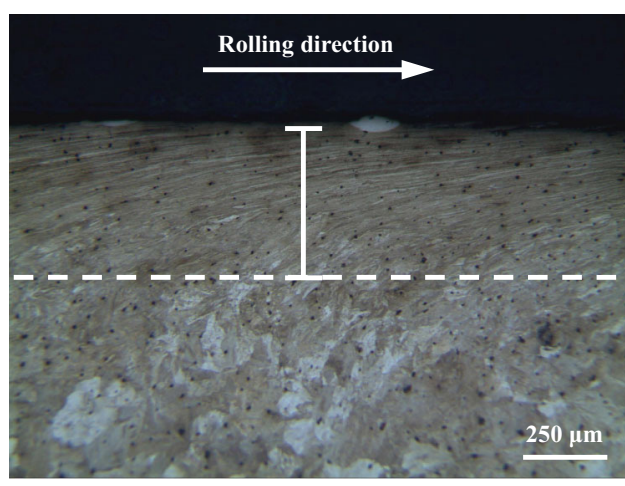

(a)

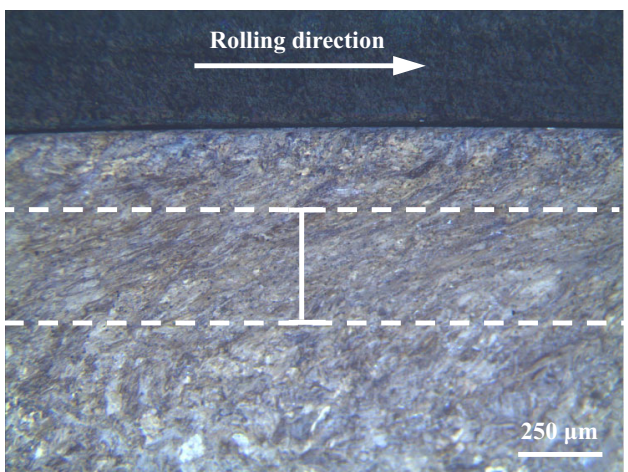

(b)
Fig. 11 OM micrographs of sectional cracks of rail discs, a W2; b O2; c G2

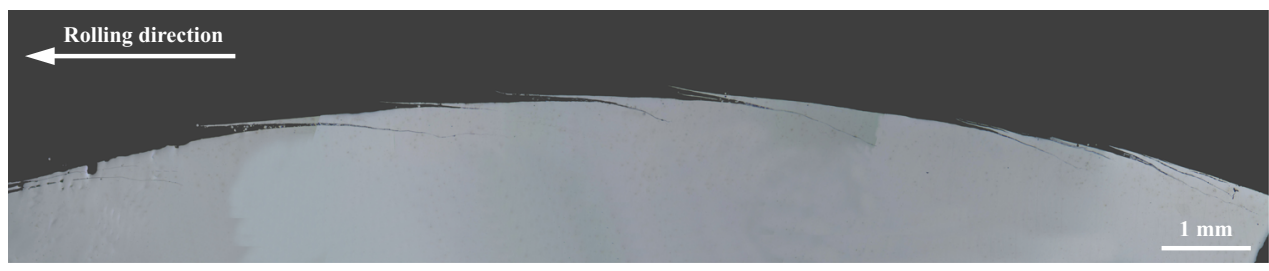

(a)

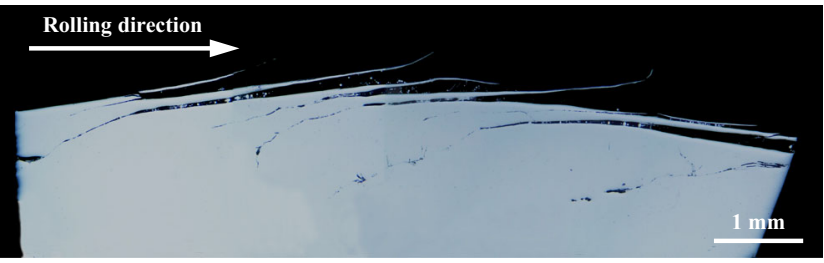

(b)

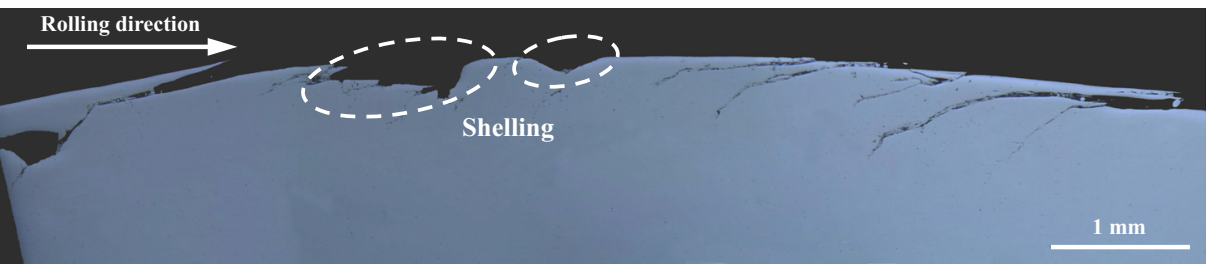

(c) 
Fig. 12 OM micrographs of sectional cracks of rail discs, a WO; b OW; c MWO

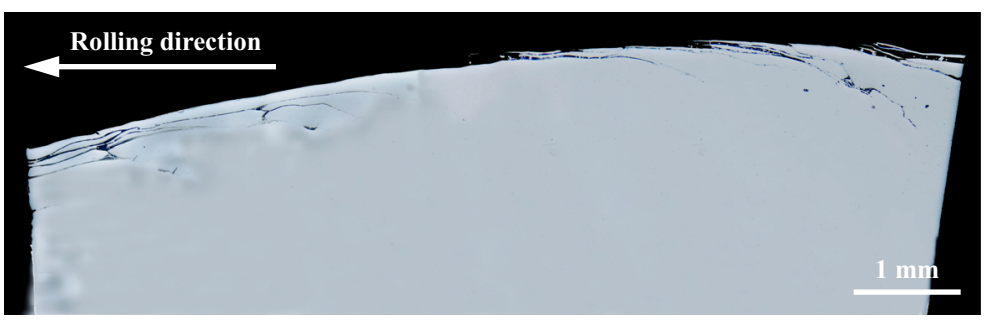

(a)

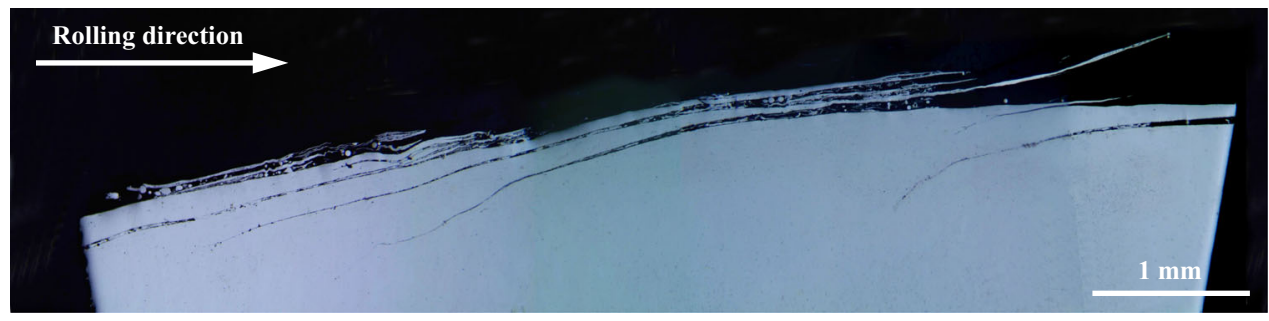

(b)

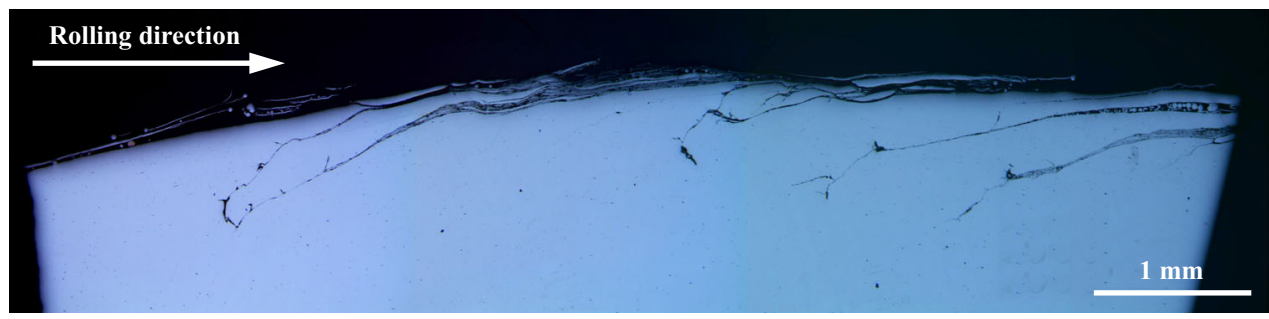

(c)

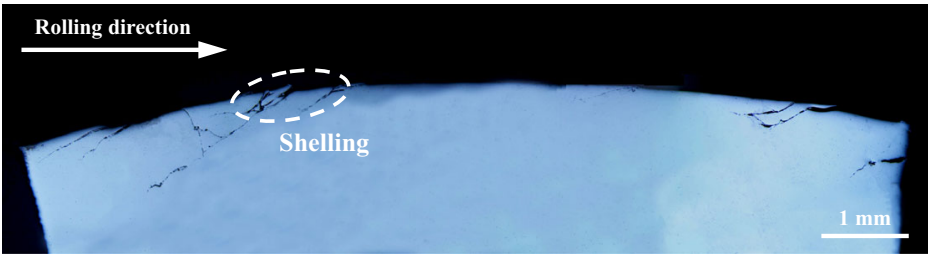

(a)

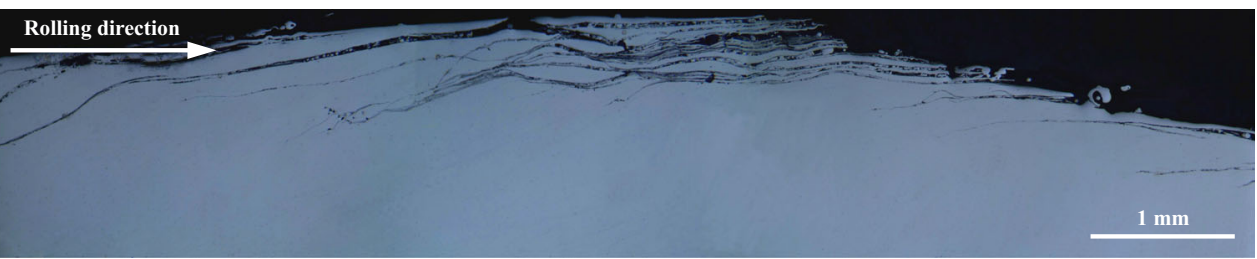

(b)

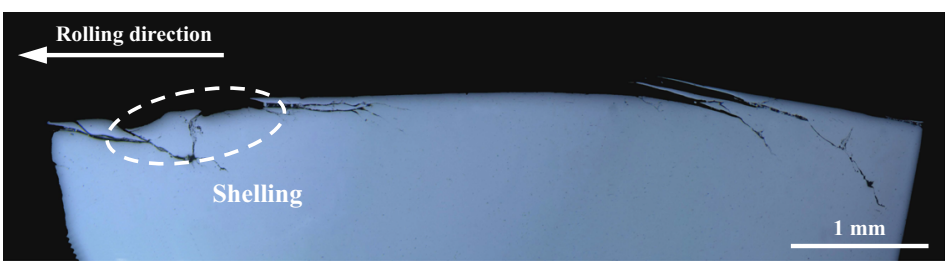

(c) 
(a)
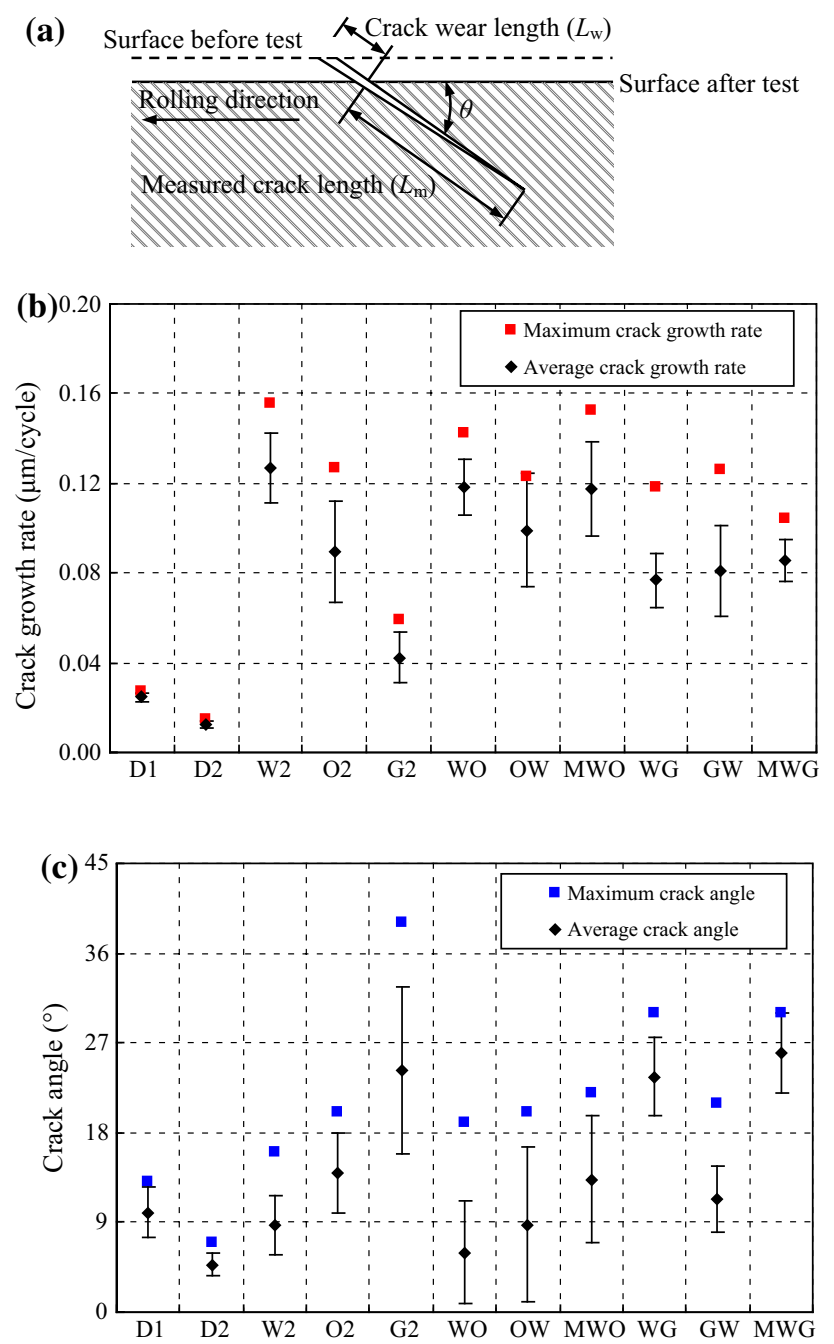

Fig. 14 Growth rate of cracks and crack angle of rail materials, a measurement of real crack growth rate; $\mathbf{b}$ growth rate; $\mathbf{c}$ crack angle

discs. It is found from Fig. 12c that there are obvious branch cracks when the water and oil are applied together (MWO test). For the WO test, slight branch cracking appears (Fig. 12a). However, when the water is applied finally, there is no visible branch cracking (Fig. 12b). There are similar results for the water and grease tests. When the water and grease are applied together (MWG test), there is visible shelling on the surface of rail disc (Figs. 5f, 13c). It is interesting that the crack growth rates of rail discs under the water and oil conditions (WO, OW, MWO tests) are less than that of the only water lubrication condition (W2 test). But, they are more than that of the oil alone lubrication condition (O2 test). The application of water and grease presents the same change. It is concluded that the lubricant types have an important influence on the propagation of cracks under the dry pre-testing condition. The water significantly accelerates the growth of RCF cracks. The effect of grease on the growth rate of cracks is the least, but the grease causes a large crack growth angle and serious branch cracking owing to different growth mechanisms.

\section{Discussion}

The rolling loading brings about plastic deformation accumulation of wheel and rail materials under the dry condition, and the plastic deformation reaches the plastic strain limit of material with increasing cycles. So, mild fatigue cracks initiate on the surface and propagate along the plastic flow line direction (Fig. 6a, b). When the cracks are pre-existing, the use of lubricants accelerates the propagation of cracks (Figs. 11, 12, 13). In this study, the tangential force of rail disc $\left(F_{\mathrm{tr}}\right)$ is consistent with the rolling direction due to a driven roller. It is observed from Fig. 15a that the cracks and deformation layer in the rail discs are significantly different to those in the wheel discs [28]. When the lubricants are applied to the contact surface of wheel/rail, the lubricants could enter the open cracks of wheel and rail discs. It is found from Fig. 15b that the root of the cracks in the wheel discs enters the contact area before the mouth and any trapped lubricant will be completely expelled when the crack passes the contact zone. So, the wheel discs experience much less crack propagation and there are no visible cracks on the contact surface. On the contrary, the mouth of the cracks in the rail disc moves through the contact zone firstly and any lubricant in the cracks will be sealed and trapped (Fig. 15b), which causes a rapid propagation of cracks due to fluid entrapment mechanism $[29,30]$. When the wheel/rail discs without dry cycling were lubricated (W1, O1 and G1 tests), the traction coefficient is low and the maximum shear stress occurs in

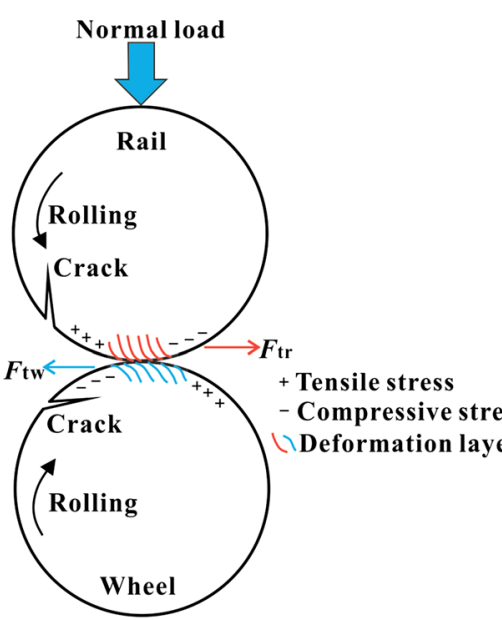

(a)

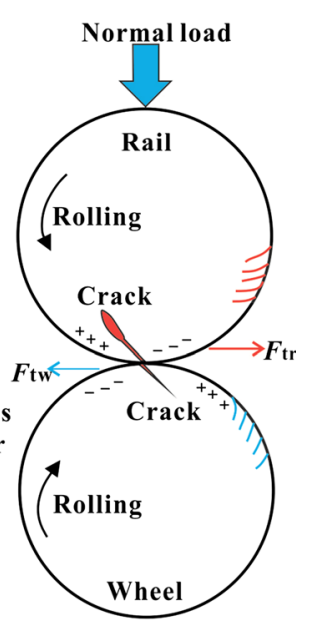

(b)
Fig. 15 Schematic representation of fatigue cracks formation, a dry condition; b fluid condition 
the sub-surface of the discs [31]. Therefore, there is no visible fatigue damage on the contact surface of rail discs after 30,000 cycles (Fig. 4c, e, g).

The lubricant trapped in the cracks helps to accelerate the growth of cracks, and the results indicate that the types or properties of lubricants have a significant influence on the propagation characteristic of cracks. There are three fluid-assisted crack growth mechanisms applicable to the cracks of rail discs, shown in Fig. 16. When the cyclic normal pressure moves near the crack, the fluid would lubricate crack faces and cyclic shear stress causes the crack propagation in Mode II (shear crack growth mechanism, Fig. 16a). The friction coefficient of crack faces has a vital effect on the crack propagation and the propagation is unlikely when the value is above 0.2 [32]. Furthermore, the crack growth decreases with an increase in the friction coefficient of the crack face. As a crack in the rail disc moves near the wheel disc, the normal load would force the fluid into the crack, which causes hydraulic crack growth in Mode I (Fig. 16b). Once the crack in the rail disc is under the wheel disc, the cyclic normal load would close the mouth of cracks and a volume of fluid is trapped in the crack cavity. Then, the fluid, due to incompressibility, is pushed towards the crack tip under the contact pressure, which causes high stress intensity and fluid entrapment crack growth in Mode I, shown in Fig. 16c.

In the cyclic normal load process, three crack growth mechanisms influence alternately the propagation of crack in the rail discs. The viscosity of lubricants is significant for crack growth. In this study, the water, oil and grease are used, respectively, and their viscosities obviously increase. The lubricant with low viscosity more easily enters the crack and flows freely in the crack. So, the shear crack growth in Mode II is significant when the water was used. Strong cyclic shear crack growth may result in obvious multi-layer small cracks and broken materials, shown in Fig. 17a. Furthermore, excellent liquidity under the water condition would trap a greater volume of fluid in the crack.
Stress intensity of crack tip due to the fluid entrapment crack growth mechanism would be increased significantly, which results in rapid growth in the crack tip (Fig. 17a). Furthermore, the main growth mode is transgranular in the crystals. Compared with the water, the grease fluid is more difficult to flow in the crack. There are no visible multilayer cracks resulting from the shear crack growth due to a higher friction coefficient in the crack faces (Fig. 17c). Furthermore, insufficient trapped fluid in the crack is very difficult to produce a high stress intensity at the crack tip. So, it is concluded that the water with lower viscosity brings the maximum growth crack rate (Fig. 14b).

It is important to identify the formation and propagation mechanisms of branch cracks under lubricated conditions. The predicted branch crack growth rates based on Mode I model was provided by Wong et al. [33]. The fluid with higher viscosity does not flow as well in the crack, and then, the hydraulic crack growth occurs more easily in the fluid filled crack, which causes crack growth along the crystal interface in the crack face (Fig. 16b). The hydraulic crack growth mechanism is beneficial to the formation and propagation of branch cracks under the cyclic loading condition. It is found that many branch cracks appear under the grease condition, shown in Fig. 17c. The propagation angle of branch cracks in Mode I is significantly different along the crystal interface direction due to weak growth resistance. So, this may result in the varieties of crack growth angles and an increase in average crack angles (Fig. 14c). Moreover, the coalescence of many branch cracks brings about the shelling damage of rail materials (Figs. 4h, 5d, f). Compared with the water and grease conditions, it is noted that the multi-layer large cracks appear owing to shear crack growth mechanism and short branch cracks is visible due to hydraulic crack growth mechanism under the oil condition (Fig. 17b). However, there are no visible broken materials in the crack face resulting from intense shear crack growth.

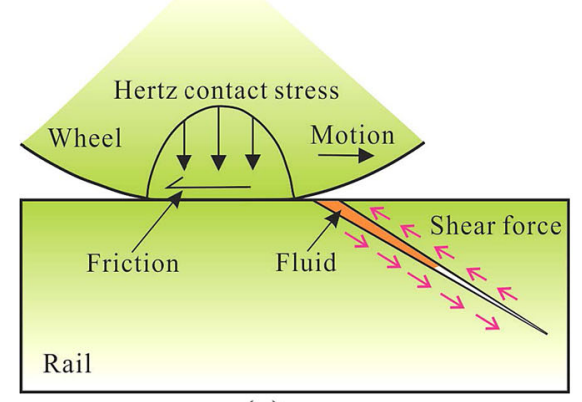

(a)

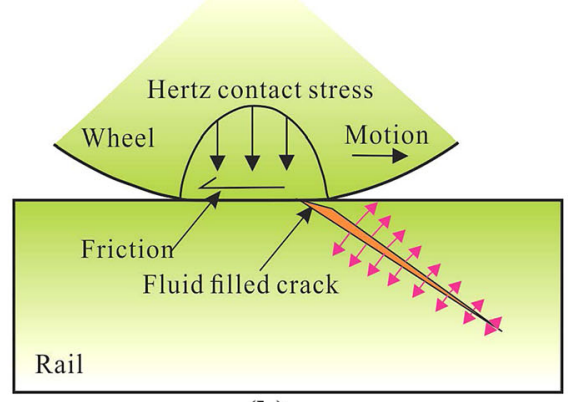

(b)

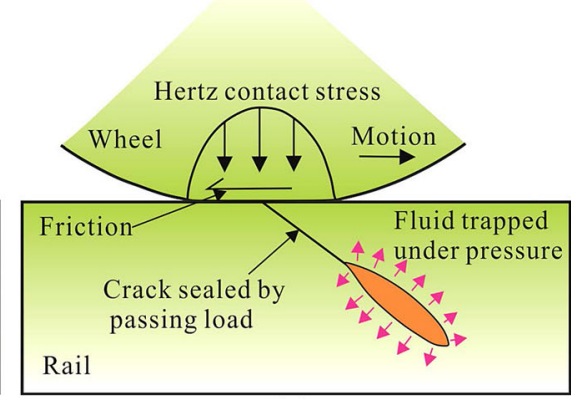

(c)

Fig. 16 Schematic representation of crack growth under the lubricant condition, a shear crack growth; b hydraulic crack growth; $\mathbf{c}$ fluid entrapment crack growth 
Fig. 17 Propagation behaviours of fatigue crack of rail discs, a W2; b O2; c G2
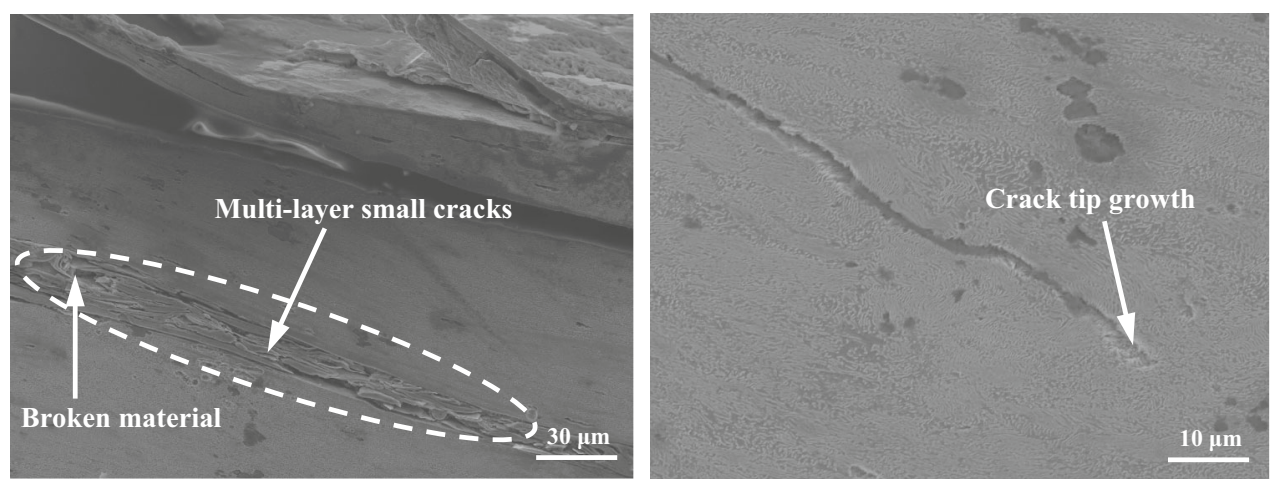

(a)
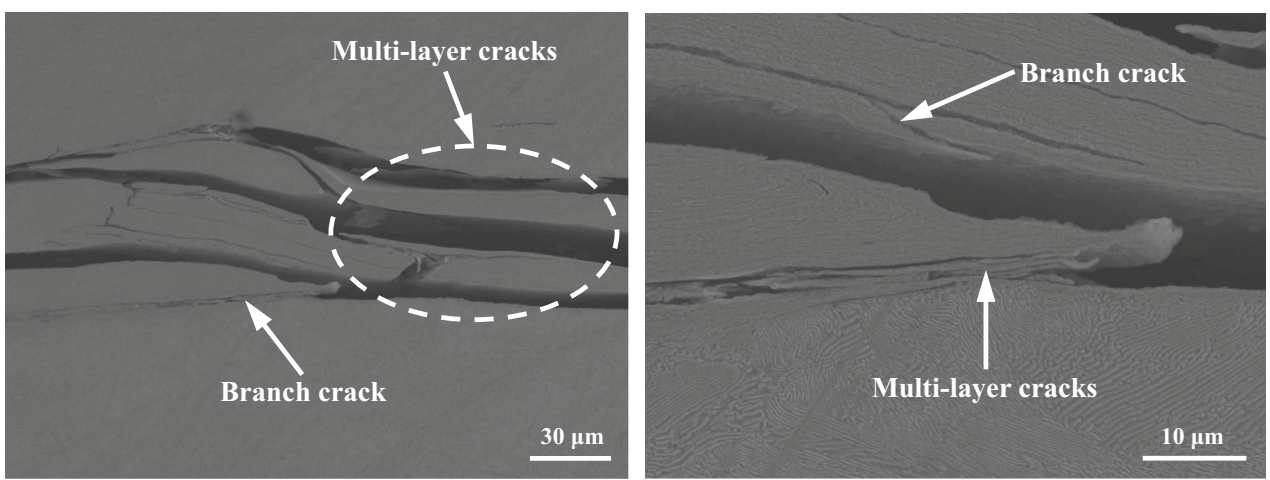

(b)
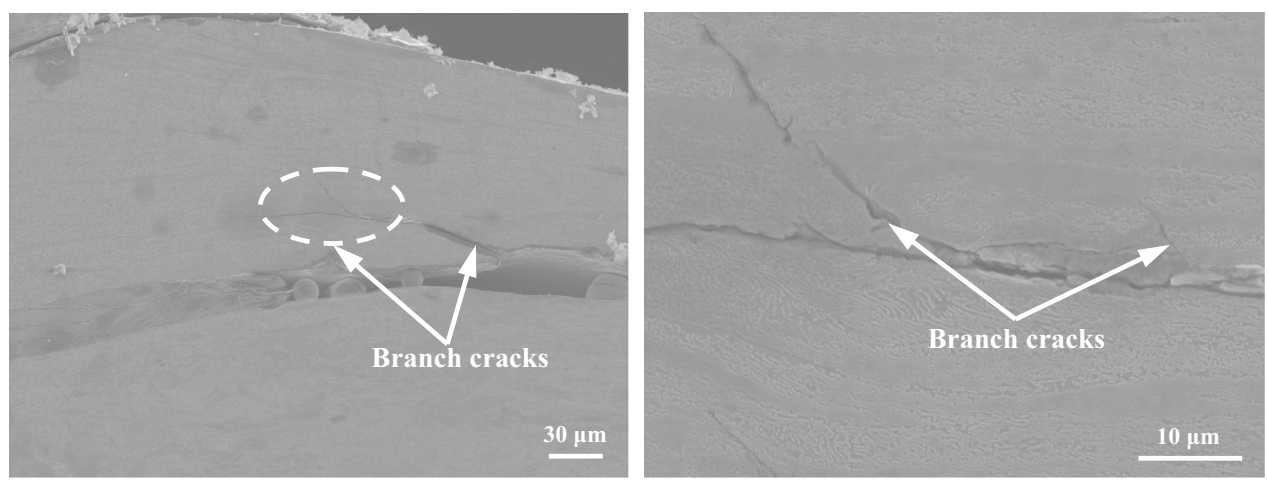

(c)

The above results indicate that the type or properties of lubricants play an important role in determining the crack growth mechanism, which causes a significant difference in crack growth rates and crack angle. When the water and oil were used together (MWO test), there are visible branch cracks and multi-layer cracks in the crack face due to the outcome of the combined action (Fig. 18a). For the MWG test, the branch cracks and multi-layer large cracks appear in the crack growth process (Fig. 18b). Of course, the crack growth mechanism is more complex due to the competitive behaviour of two lubricants. Furthermore, the different application order of two lubricants (WO, OW, WG, GW tests) would transform the dominating crack growth mechanism, which significantly influences the crack growth angles (Fig. 14c).

It is worth noting that cracks usually propagate parallel to the aligned pearlite lamellas in the deformed microstructure close to the surface under the dry condition [34]. However, the crack growth path would become more complicated owing to different crack growth mechanisms resulting from fluid lubrication. In fact, fluid pressure acting on the crack faces and friction forces acting between the crack faces are particularly important in determining the growth behaviours of cracks. In view of crack dynamic growth characteristics, further work on the crack propagation path under different lubricants and application order 
Fig. 18 Propagation behaviours of fatigue crack of rail discs, a MWO; b MWG

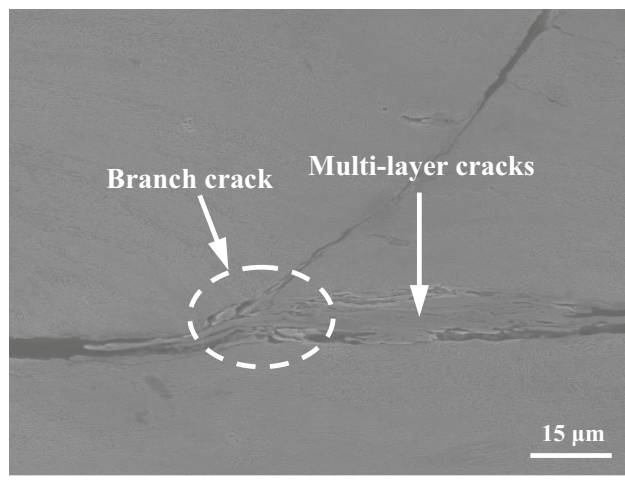

(a)

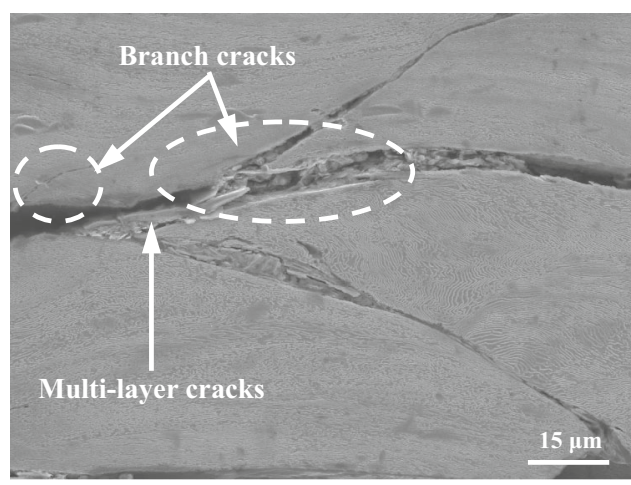

(b) conditions should be clarified by means of a numerical evaluation method.

\section{Conclusions}

1. Under the dry 5000 cycles pre-testing condition, the application of lubricants has an important role in the wear and RCF crack characteristics of rail materials. The types or properties of lubricants affect the tractive coefficient of wheel/rail interface and rail material removal, which causes a remarkable difference in wear rate of rail materials.

2. The wear damage mechanism has a transformation from mild surface damage to serious surface delamination and fatigue cracks when the lubricants are applied after 5000 cycles dry pre-testing. Lubricant types and application order result in different degree of damage and hardening behaviour of rail rollers.

3. The water, oil and grease cause significantly different crack growth rates and crack angle due to different crack growth mechanisms. The water brings about the maximum crack growth rate and smallest crack angle. It is noted that different application orders of two lubricants significantly influence on the crack growth angles of rail materials.

4. Three fluid-assisted crack growth mechanisms are beneficial to the propagation of RCF cracks under the lubricating condition. The types and properties of lubricants have a vital influence on the crack growth characteristics of rail materials. Lubricants with low viscosity (water) tend to bring shear crack growth and fluid entrapment crack growth. With an increase in the viscosity, the hydraulic crack growth mechanism enhances, which results in the appearance of many branch cracks.

Further work on crack growth modelling under different lubricants and application orders conditions should be performed for better understanding the crack dynamic growth mechanism and path.

Acknowledgements The first author would thank the State Scholarship Fund of China Scholarship Council (CSC) for pursuing study in the University of Sheffield as an Academic Visitor. The authors are grateful to Mr. Cheng-gang He, Ms. Lei Ma and Mr. Xiang-ji Zhao for their kind help in analysing the damage behaviours of specimens.

Open Access This article is distributed under the terms of the Creative Commons Attribution 4.0 International License (http://creative commons.org/licenses/by/4.0/), which permits unrestricted use, distribution, and reproduction in any medium, provided you give appropriate credit to the original author(s) and the source, provide a link to the Creative Commons license, and indicate if changes were made.

\section{References}

1. Hardwick, C., Lewis, R.: The effects of alternative top of rail friction materials on pre-existing rolling contact fatigue cracks. In: Pombo, J. (ed.) Proceedings of the Second International Conference on Railway Technology: Research, Development and Maintenance, pp. 1-17. Civil-Comp Press, Stirlingshire, Scotland (2014)

2. Fletcher, D., Franklin, F.: Rail surface fatigue and wear. In: Lewis, R., Olofsson, U. (eds.) Wheel-Rail Interface Handbook. Woodhead Publishing Ltd, Cambridge (2009)

3. Fletcher, D.I., Smith, L., Kapoor, A.: Rail rolling contact fatigue dependence on friction, predicted using fracture mechanics with a three-dimensional boundary element model. Eng. Fract. Mech. 76(17), 2612-2625 (2009)

4. He, C.G., Huang, Y.B., Ma, L., Guo, J., Wang, W.J., Liu, Q.Y., Zhu, M.H.: Experimental investigation on the effect of tangential force on wear and rolling contact fatigue behaviors of wheel material. Tribol. Int. 92, 307-316 (2015)

5. Garnham, J.E., Davis, C.L.: The role of deformed rail microstructure on rolling contact fatigue initiation. Wear 265(9-10), 1363-1372 (2008)

6. Reza, M.N., Mahmoud, S., Khalil, F.: Effect of wear on rolling contact fatigue crack growth in rails. Tribol. Int. 94, 118-125 (2016)

7. Kapoor, A., Fletcher, D.I., Franklin, F.J.: The role of wear in enhancing rail life. In: Proceedings of the 29th Leeds-Lyon Symposium on Tribology, vol. 41(3), pp. 331-340 (2003)

8. Wang, W.J., Guo, J., Liu, Q.Y., Zhu, M.H., Zhou, Z.R.: Study on relationship between oblique fatigue crack and rail wear in curve track and prevention. Wear 267(1-4), 540-544 (2009) 
9. Donzella, G., Faccoli, M., Ghidini, A., Mazzu, A., Roberti, R.: The competitive role of wear and RCF in a rail steel. Eng. Fract. Mech. 72(2), 287-308 (2005)

10. Franklin, F.J., Gahlot, A., Fletcher, D.I., Garnham, J.E., Davis, C.: Three-dimensional modelling of rail steel microstructure and crack growth. Wear 271(1-2), 357-363 (2011)

11. Carroll, R.I., Beynon, J.H.: Decarburisation and rolling contact fatigue of a rail steel. Wear 260(4-5), 523-537 (2006)

12. Sandstrom, J.: Subsurface rolling contact fatigue damage of railway wheels - a probabilistic analysis. Int. J. Fatigue 37(4), 146-152 (2012)

13. Yates, J.R., Zanganeh, M., Tomlinson, R.A., Brown, M.W., Diaz Garrido, F.A.: Crack paths under mixed mode loading. Eng. Fract. Mech. 75(3-4), 319-330 (2008)

14. Makino, T., Kato, T., Hirakawa, K.: The effect of slip ratio on the rolling contact fatigue property of railway wheel steel. Int. J. Fatigue 36(1), 68-79 (2012)

15. Fletcher, D.I., Hyde, P., Kapoor, A.: Modelling and full-scale trials to investigate fluid pressurization of rolling contact fatigue cracks. Wear 265(9-10), 1317-1324 (2008)

16. Cookson, J.M., Mutton, P.J.: The role of the environment in the rolling contact fatigue cracking of rails. Wear 271(1-2), 113-119 (2011)

17. Lewis, S.R., Lewis, R., Evans, G., Buckley-Johnstone, L.E.: Assessment of railway curve lubricant performance using a twindisc tester. Wear 314(1-2), 205-212 (2014)

18. Zhu, Y., Sundh, J., Olofsson, U.: A tribological view of wheelrail wear maps. Int. J. Railw. Technol. 2, 79-91 (2013)

19. Descartes, S., Saulot, A., Godeau, C., Bondeux, S., Dayot, C., Berthier, Y.: Wheel flange/rail gauge corner contact lubrication: tribological investigations. Wear 271(1-2), 54-61 (2011)

20. Cann, P.M.: The leaves on the line problem-a study of leaf residue film formation and lubricity under laboratory test conditions. Tribol. Lett. 24(2), 151-158 (2006)

21. Lewis, R., Gallardo, E.A., Hilton, T., Armitage, T.: Effect of oil and water mixtures on adhesion in the wheel/rail contact. Proc. Inst. Mech. Eng. Part F J. Rail Rapid Transit 223(3), 275-283 (2009)

22. Wang, W.J., Liu, T.F., Wang, H.Y., Liu, Q.Y., Zhu, M.H., Jin, X.S.: Influence of friction modifiers on improving adhesion and surface damage of wheel/rail under low adhesion conditions. Tribol. Int. 75(5), 16-23 (2014)

23. Li, Z., Arias-Cuevas, O., Lewis, R., Gallardo-Hernandez, E.A.: Rolling-sliding laboratory tests of friction modifiers in leaf contaminated wheel-rail contacts. Tribol. Lett. 33(2), 97-109 (2009)

24. Lu, X., Cotter, J., Eadie, D.T.: Laboratory study of the tribological properties of friction modifier thin films for friction control at the wheel/rail interface. Wear 259(7), 1262-1269 (2005)

25. Hardwick, C., Lewis, R., Eadie, D.T.: Wheel and rail wearunderstanding the effects of water and grease. Wear 314(1-2), 198-204 (2014)

26. Fletcher, D.I., Beynon, J.H.: Development of a machine for closely controlled rolling contact fatigue and wear testing. J. Test. Eval. 28(4), 267-275 (2000)

27. Tyfour, W.R., Beynon, J.H., Kapoor, A.: Deterioration of rolling contact fatigue life of pearlitic rail steel due to dry-wet rollingsliding line contact. Wear 197(1-2), 255-265 (1996)

28. Beynon, J.H., Garnham, J.E., Sawley, K.J.: Rolling contact fatigue of three pearlitic rail steels. Wear 192(1-2), 94-111 (1996)

29. Kaneta, M., Murakami, Y.: Propagation of semi-elliptical surface cracks in lubricated rolling/sliding elliptical contacts. Trans. ASME 113, 270-275 (1991)

30. Tunna, J., Sinclair, J., Perez, J.: A review of wheel wear and rolling contact fatigue. Proc. Inst. Mech. Eng. Part F J. Rail Rapid Transit 221(2), 271-289 (2007)

31. Seo, J.W., Kwon, S.J., Lee, D.H., Choi, H.Y.: Analysis of contact fatigue crack growth using twin-disc tests and numerical evaluations. Int. J. Fatigue 55, 54-63 (2013)

32. Bower, A.F.: The influence of crack face friction and trapped fluid on rolling contact fatigue cracks. ASME J. Tribol. 110(4), 704-711 (1988)

33. Wong, S.L., Bold, P.E., Brown, M.W., Allen, R.J.: A branch criterion for shallow angled rolling contact fatigue cracks in rails. Wear 191(1-2), 45-53 (1996)

34. Larijani, N., Brouzoulis, J., Schilke, M., Ekh, M.: The effect of anisotropy on crack propagation in pearlitic rail steel. Wear 314(1-2), 57-68 (2014) 